\title{
Melanomacrophages and melanomacrophage centres in Osteichthyes
}

\author{
MICHAE P. STOSIK ${ }^{1}$, BEATA TOKARZ-DEPTU $A^{2}$, WIESŁAW DEPTUŁA ${ }^{3}$ \\ ${ }^{1}$ Department of Microbiology and Genetics, Faculty of Biological Sciences, University of Zielona Gora, Poland \\ ${ }^{2}$ Department of Immunology, Faculty of Biology, University of Szczecin, Poland \\ ${ }^{3}$ Centre for Veterinary Sciences, Nicolaus Copernicus University in Torun, Poland
}

\begin{abstract}
Melanomacrophages (MMs) are phagocytizing cells with high amounts of pigments including melanin which can be found in a number of cold-blooded species. In Osteichthyes, these cells cluster to form so-called melanomacrophage centres (MMCs), which are predominantly present in the stroma of hematopoietic and lymphoid tissues, that is, in the kidney and spleen. The functionality of MMs and $M M C s$ results from their involvement and role in the defence reactions, related to both the innate and the adaptive immune mechanisms, and in processes unrelated to defence functions as well. There is evidence that MMCs are structurally and functionally similar to mammals' germinal centres (GCs). It appears that mature IgM+B cells in Osteichthyes can be the equivalent of mIgM+ centrocytes in mammals, whereas MMs can be, in terms of the function, the equivalent of follicular dendritic cells (FDCs), and MMCs can be, in terms of clustered specific cells, the equivalent of GCs. This paper presents selected facts about the structural and functional similarity between GCs and MMCs and about the involvement and role of MMCs and MMs in the immune response. The facts help get a proper picture of the location of MMs and MMCs within the structure of the fish immune system, also in the context of their evolutionary relationship with GCs and of the possibility of pointing out the evolutionary closeness between MMCs in Osteichthyes and GCs in mammals.
\end{abstract}

Key words: fish, immune response, melanomacrophages, melanomacrophage centres.

(Centr Eur J Immunol 2019; 44 (2): 201-205)

\section{Introduction}

Melanomacrophages (MMs) are phagocytizing cells with high amounts of melanin, lipofuscin and hemosiderin, and are present in a number of cold-blooded species, including fish. In Osteichthyes, these cells cluster to form so-called melanomacrophage centres (MMCs) which are predominantly present in the stroma of hematopoietic and lymphoid tissues, that is, in the anterior kidney, the spleen and the posterior kidney. However, the degree of clustering of MMs in the organs varies from large clusters in the spleen to considerably smaller clusters in the anterior kidney [1-4]. MMCs are also occasionally found in the liver and in other body parts of this fish [1-4]. The role of MMs and MMCs in the development of the defence reaction in fish, in response to an antigen, was indicated by Ellis and De Sous as early as in 1974 [2, 5]. These authors identified MMCs as the likely place where the antigen, being uptaken by MMs, can react with the immune system units - the lymphocytes in which signals initiating specific immunity are generated $[2,5]$. Retention of the antigen in the MMCs, and, in further stages, the activation of macrophages and lymphocytes, the synthesis and secretion of antibodies and the development of immunological memory are highly likely, as proved by Press et al. [6] in their studies on Atlantic salmon (Salmo salar). Moreover, it has been shown that MMCs are places where antigens, including those bound to antibodies and thus forming soluble immune complexes, can be stored for a long while [4, 5, 7-9]. For this reason, the functionality of MMs and MMCs is considered in the context of their involvement and role in the immune reactions with regard to both the innate and the adaptive immune mechanisms. Aside from that, the role of MMs and MMCs is also discussed in the context of processes unrelated to the very defence mechanisms conditioned by, inter alia, their involvement in uptaking and storing iron as well in melanogenesis [2, 4]. It should be added that the range of activities of MMs clustered in MMCs is regarded as primal in relation to the processes related to the involvement and role of these cells in immune reactions such as antigen uptake, fulfillment of the role of a cell presenting the antigen to lymphocytes and sequestration of the products of cell degradation or of foreign substances of endogenous and exogenous origin $[2,4$,

Correspondence: Prof. Michał P. Stosik, Department of Microbiology and Genetics, Faculty of Biological Sciences, University of Zielona Gora, 1 Prof. Z. Szafrana St., 65-516 Zielona Gora, Poland, e-mail: m.stosik@wnb.uz.zgora.pl Submitted: 20.02.2018; Accepted: 13.03.2018 
10-12]. Studies have also shown that the quantity and size of MMCs increase in fish under increasing environmental stress. This provides an opportunity to use the "melanomacrophage picture" as a biomarker for the state of fish health and for the quality of the aquatic environment $[2,7$, 11]. Despite a certain structural and functional similarity between fish MMCs in fish and germinal centres (GCs) in mammalian lymph nodes, and despite the hypothesis that the centres can be considered to be evolutionary precursors or primitive analogues of GCs, they still require further research $[2,4,7,9,12,13]$.

\section{Structural and functional similarity between GCs and MMCs}

GCs in mammals have been thoroughly examined in respect of their structural and functional properties. The centres have been proven to be clusters of antigen-induced B cells with a phenotype of CD19+ mIgM+ (membrane IgM) in the secondary organs of the lymphatic system where CD77+ mIgM+ centroblasts develop as a result of blastic proliferation. Subsequently, following somatic hypermutation in the genes coding the variable part of the antibody, mIgM+ centrocytes develop and the membrane Ig appear in them again $[4,14,15]$. GCs are thus characterized by the presence of specific B cells, follicular dendritic cells (FDCs) and follicular helper CD4 T cells (TFH) $[4,14,15]$. The B cells in those centres differentiate into memory B cells and plasma cells, including early plasmacytes of CD19+ CD24+ CD38+ CD138+ and mature plasmacytes with phenotypes of CD38+CD44+CD49d+ CD19+ $[4,14,15]$.

No GCs structurally and functionally identical with mammalian GCs have been found in Osteichthyes. Regardless of that, however, a number of studies on fish [16-18] have shown the immune system units' ability to react and respond to antigenic stimulation which is expressed in producing and secreting highly specific antibodies with mature affinity. The results presented by Saunders et al. [5], which pertained to the occurrence of activation-induced cytidine deaminase (AID+) B cells and T CD4+ and TcR $\beta+$ cells in the very melanomacrophage environment, suggest that the $B$ cell affinity maturation in fish should be perceived as a process being controlled, in the early stage of vertebrate evolution, by structures resembling or similar to GCs. According to Steinel and Bolnick [4], previous studies and analyses have shown that despite the many structural, cellular and molecular similarities between MMCs in Osteichthyes and GCs in mammals, it would appear more appropriate to accept a hypothesis restricted to the important role of MMCs in activating adaptive immunity in fish. Many relevant studies have been carried out on these animals [4-12, $16,17,19,20]$, allowing us to develop a thesis that there are structural and functional elements in fish which involve the development of an ability to generate memory B cells and plasma cells with high affinity. These cells are supposed to be the earlier evolutionary forms of mammalian GCs. Moreover, studies have shown similarities between fish MMs and FDCs, specialized in presenting the antigen to B lymphocytes, and between mammalian tingible body macrophages (TBMs), a type of macrophage that is found in GCs containing phagocytized apoptotic cells at different stages of degradation, and red pulp macrophages (RPMs) of the spleen, affected by hemosiderin [4]. The properties of fish macrophages that are important in the context of the relationships with GCs discussed in this paper include the ability of these cells to cluster forming MMCs, the ability to phagocytize, including to erythrophagocytize, the positive result in response to monoclonal antibodies (CNA.42) against FDCs and the expression of the colony stimulating factor 1-receptor (CSF1-R) [4, 5]. MMs are also characterized by that they are present amongst immune complexes and in close proximity to cells expressing AID in antigen-activated B cells $[4,5]$. According to Saunders et al. [5], the ring of MMs surrounding a mixture of AID+ B cells can be considered as the natural organization of MMCs in the spleen and posterior kidneys. Findings from previous studies [4-12, 16, 17, $19,20]$ show that MMCs are structurally and functionally similar to GCs in mammals. This is also supported by the fact that MMCs respond to infection or immunization by increasing their sizes and cluster quantities, as it is observed in mammalian GCs $[8,20]$, although, as reported by Herráez and Zapata [8], such a reaction is not accompanied by any increase in the synthesis or secretion of antibodies. Steinel and Bolnick [4] have also drawn attention to the fact that for fish, irrespective of the expression of AID B cells, there is no evidence for somatic hypermutation (SHM) of antibody coding genes in the hypervariable regions that determine the antibody's specificity, as has been proved by Saunders $e t$ $a l$. in their research [5]. Pointing out the structural, cellular and molecular similarities between MMCs in fish and GCs in mammals, Steinel and Bolnick [4] imply that there is an evolutionary relationship between those cells and specific immunity in mammals. Those authors [4] emphasize, at the same time, the need for undertaking further research into the functional properties of MMCs, with the issues of proliferation and differentiation of B cells and of hypermutation of antibody coding genes in the hypervariable regions considered as processes dependent on MMCs, taking place inside MMCs or related to these clusters. The issues concerning the functional relations between B cells and TFH lymphocytes in a reaction with the involvement of T-dependent antigens that induce reactions within GCs as well as of T-independent antigens need to be clarified, also in the context of differentiation and clonal expansion of B cells, because T lymphocytes, especially TFH, are responsible for the stimulation of the proliferation and differentiation of $\mathrm{B}$ lymphocytes into GCs, and for the development of the immunological memory as well [4]. 


\section{Involvement and role of MMCs and MMs in the immune response}

The defence functions of MMCs are conditioned by, apart from other things, the immunological activity of MMs including phagocytosis of infectious material particles and erythrophagocytosis [4] as well as the function of antigen-presenting cells (APCs), just as is the case with FDCs in mammals, hence the involvement of these structures in the development of the innate and adaptive immune response $[4,12,19]$. However, it should be stressed that the most important functions of MMs clustered in MMCs include the ability of these cells to accumulate, destroy, detoxicate and recycle endogenous and exogenous substances that are metabolically foreign, including damaged erythrocytes, and to store compounds resulting from erythrophagocytosis of, inter alia, iron and phospholipids $[2,4,21]$. This role of MMs and MMCs can also be seen during the ageing process in fish and during the subsequent process of tissue destruction in these animals $[2,21]$.

In Osteichthyes, both the spleen and the posterior kidney are peripheral lymphoid organs in which a specific humoral immune response develops after antigen presentation. The anterior kidney in Osteichthyes, equivalent to bone marrow in mammals, is the central lymphoid organ in which B cells develop and mature [22-25]. This organ constitutes a core element for the development of specific humoral immunity in these animals. These cells come from a common lymphocyte progenitor (CLP) and their subsequent developmental stages are pro-B cells, large and small pre-B cells as well as immature and mature B cells $[22,23,25]$. Primary mature naive $B$ cells migrate from the anterior kidney to the blood stream and to the peripheral lymphoid organs, i.e. the spleen and posterior kidney where they are subject to antigenic stimulation [5, 23]. The differentiation of B cells in the spleen and posterior kidney eventually results in the development of plasmablasts and plasma cells which, at the next stage, migrate from the spleen to the anterior kidneys [23, 26, 27]. At different stages of the B cell differentiation in Osteichthyes and of the immune response development, the cells are recognised based on their phenotype - a picture of combined expression of specific transcription factors and class $\mathrm{M}$ immunoglobulins (IgM), including membrane (mIgM) and secretory ( $\operatorname{sgM}$ ) immunoglobulins [22-25, 28-33]. It has been proven that in the anterior kidney, mature naive $\mathrm{B}$ cells primary $\mathrm{B} \operatorname{IgM}+(\mathrm{sIgM}+\mathrm{mIgM}+) \operatorname{IgD}+(\mathrm{mIgD}+)$ cells develop from immature IgM+ $(\mathrm{mIgM}+) \mathrm{B}$ cells and migrate to the blood stream, spleen and posterior kidney [22, 23]. Then, following antigen recognition, they are subject to antigen activation by MMs - the antigen-presenting cells and by T lymphocytes, and this is the initial phase of the activation of $\mathrm{B}$ and $\mathrm{T}$ lymphocytes (just as in mammals) $[5,23]$. The IgM+ B cells, antigen-activated within MMCs (in mammals, the stage of development of GCs in lymphat- ic follicles, the dark zone of GCs, respectively) are subject, just as is the case with mammals, to somatic hypermutation that is responsible for so-called affinity maturation (AID is expressed in B cells) and to proliferation. As a result, mature IgM+ B cells develop and this process can be considered equivalent to positive selection [5]. It should be added that AID expression was only observed in IgM+ IgD- B cells in absence of such a reaction in mature naive $B$ cells with a phenotype of IgM+ IgD+. It should also be pointed out that in fish, at a similar location, $\mathrm{T}$ cell receptor beta (TcR $\beta$ ) chains, CD4 transcripts and the MHC class II immunoglobulin heavy chain are expressed [5]. It is also worth noting that such cells in mammals form GCs making up a cluster of antigen-induced B cells in the secondary organs of the lymphatic system. There, in mammalian GCs, the blastic proliferation of CD19+ mIgM+ $\mathrm{B}$ cells leads to the development of proliferating CD77 $\mathrm{mIg}$ - centroblasts in the dark zone of GCs and to the subsequent development of $\mathrm{mIg}+$ centrocytes migrating to the light zone of GCs where re-expression of Ig takes place [5]. According to Saunders et al. [5], in Osteichthyes Ictalurus punctatus - AID-expressing B cells, as an equivalent of the dark zone GCs in mammals, alternate with MMs or are surrounded by a cluster of CSF1-R+ pigment cells making up MMCs. It is also worth emphasizing the fact that to these authors [5] it seemed highly unlikely that the expression of the mutation enzyme called AID could be possible in cold-blooded vertebrates in absence of GCs or in absence of cell selection locations after mutations with the involvement of AID. However, IgM+ B cells in Osteichthyes may be an equivalent of centrocytes (IgM+) in mammals and may be subject to processes typical of the $B$ cell selection area in these animals, that is, of the light zone of GCs. In the next stages of the process development in fish MMCs and in mammalian GCs, mature IgM+ $\mathrm{B}$ cells are re-activated following somatic hypermutation in the genes coding the variable part of the antibody after the recognition of the antigen, its endocytosis via membrane Ig and after its processing and presentation in the complex with MHC II to TFH lymphocytes, and, as it can be assumed, the B cells are re-selected with respect to their antigen affinity, or are verified for antigen specificity that also refers to TFH lymphocytes [5, 23, 24, 28, 34]. Ultimately, the differentiation of B cells is activated in fish under the action of the cytokines released by TFH and leads to the development of memory cells, antibody secreting cells (ASCs), i.e. proliferating Pax5.PD+ mIgM+ plasmablasts, characterized by an increase in the synthesis and secretion of $\operatorname{IgM}[26,27]$, short-lived IgM+ plasma cells that remain in the spleen for a long time [23, 26, 27], and of long-lived, non-proliferating Pax5.PD- mIgM plasma cells that migrate back to the anterior kidney [5, 23, 25-28, 35], which is the main area where mature plasma cells with a phenotype of Pax5.PD- mIgM- can be found $[25,28]$. These cells in the anterior kidney are character- 
ised by a great ability to synthesize and secrete $\operatorname{IgM}(\mathrm{sIgM}$, mIgM), and the antigen "taken" and processed by these cells is presented to CD4 Th-lymphocytes in the form of a complex with the MHC II protein. It is also worth mentioning that in Osteichthyes, the increase in the affinity of antibodies, just as the increase in the intensity of secretion of IgM antibodies, only requires little enzymatic interference to considerably increase the general avidity of each polymeric molecule $[16,36]$. Mature IgM+ B cells in Osteichthyes can thus be the equivalent of $\mathrm{mIgM}+$ centrocytes in mammals, whereas MMs can be, in terms of function but not origin, the equivalent of FDCs and GCs, and in terms of clustered cells, the equivalent of MMCs.

\section{Conclusions}

Regardless of the data presented, there is still a justified need for exploring and explaining the picture related to the properties and functions of MMs and MMCs in Osteichthyes, also in the context of their evolutionary relationship with GCs in mammals. The exploration of the knowledge on, inter alia, the histological properties of MMCs or on the molecular structure of the elements conditioning the specific immunity mechanisms in specific locations and stages of their activity, to the extent and degree allowing for their phenotype identification, will provide an opportunity to indicate the equivalents or equally important components of the mammalian immune system and to better assess the maturity of the defence system in Osteichthyes. It is also worth emphasizing that the organization of the immune system structures and of the components of the defence system in fish, including MMs and MMCs involved in the development of the innate and adaptive immunity mechanisms should be considered in the context of the evolutionary position of these animals, especially in the context of related natural domination of the innate immunity mechanisms that are more mature than the adaptive immunity mechanisms.

\section{The authors declare no conflict of interest.}

\section{References}

1. Agius C (1981): Preliminary studies on the ontogeny of the melano-macrophages of teleost haemopoietic tissue and agerelated changes. Dev Comp Immunol 5: 597-606.

2. Agius C, Roberts RJ (2003): Melano-macrophage centres and their role in fish pathology. J Fish Dis 26: 499-509.

3. Uribe C, Folch H, Enriquez R, Moran G (2011): Innate and adaptive immunity in teleost fish: a review. Vet Med (Praha) 56: 486-503.

4. Steinel NC, Bolnick DI (2017): Melanomacrophage centers as a histological indicator of immune function in fish and other poikilotherms. Front Immunol 8: 827.
5. Saunders HL, Oko AL, Scott AN, et al. (2010): The cellular context of AID expressing cells in fish lymphoid tissues. Dev Comp Immunol 34: 669-676.

6. Press C, Evensen O, Reitan LJ, Landsverk T (1996): Retention of furunculosis vaccine components in Atlantic salmon, Salmo salar L., following different routes of administration. J Fish Dis 19: 215-224.

7. Agius C (1985): The melano-macrophage centres in fish: a review. In: Fish Immunology. Manning MJ, Tatner MF (eds.). Academic Press, London: 85-105.

8. Herráez MP, Zapata AG (1987): Trapping of intraperitoneal-injected Yersinia ruckeri in the lymphoid organs of Carassius auratus: the role of melano-macrophages centres. J Fish Biol 31: 235-237.

9. Lamers CH, De Haas MJ (1985): Antigen localization in the lymphoid organs of carp (Cyprinus carpio). Cell Tissue Res 242: 491-498.

10. Agius C (1980): Phylogenetic development of melano-macrophage centres in fish. J Zool 191: 11-31.

11. Evans D, Nowak B (2016): Effect of ranching time on melanomacrophage centres in anterior kidney and spleen of Southern bluefin tuna, Thunnus maccoyii. Fish Shellfish Immunol 59: 358-364.

12. Vigliano FA, Bermudez R, Quiroga MI, Nieto JM (2006): Evidence for melano-macrophage centres of teleost as evolutionary precursors of germinal centres of higher vertebrates: an immunohistochemical study. Fish Shellfish Immunol 21: 467-471.

13. Ellis AE (1980): Antigen-trapping in the spleen and kidney of the plaice, Pleuronectes platessa (L.). J Fish Dis 3: 413-426.

14. Baran T, Boratyńska M (2017): Immunoregulacyjna rola limfocytów B w odpowiedzi na alloprzeszczep nerki. Postepy Hig Med Dosw 71: 254-266.

15. Feliksbrot ME, Król MA, Dwilewicz-Trojaczek J (2005): Limfopoeza komórek B u człowieka. Adv Clin Exp Med 14: 1033-1040.

16. Kaattari SL, Zhang HL, Khor IW, et al. (2002): Affinity maturation in trout: clonal dominance of high affinity antibodies late in the immune response. Dev Comp Immunol 26: 191200.

17. Solem ST, Stenvik J (2006): Antibody repertoire development in teleosts - a review with emphasis on salmonids and Gadus morhua L. Dev Comp Immunol 30: 57-76.

18. Sunyer JO (2013): Fishing for mammalian paradigms in the teleost immune system. Nat Immunol 14: 320-326.

19. Diaz-Satizabal L, Magor BG (2015): Isolation and cytochemical characterization of melanomacrophages and melanomacrophage clusters from goldfish (Carassius auratus, L.). Dev Comp Immunol 48: 221-228.

20. Kranz H (1989): Changes in splenic melano-macrophage centers of dab Limanda limanda during and after infection with ulcer disease. Dis Aquat Organ 6: 167-173.

21. Brown CL, George CJ (1985): Age-dependent accumulation of macrophage aggregation in the yellow perch, Perca flavescens (Mitchill). J Fish Dis 8: 135-138.

22. Zwollo P (2011): Dissecting teleost B cell differentiation using transcription factors. Dev Comp Immunol 35: 898-905.

23. Zwollo P, Cole S, Bromage E, Kaattari S (2005): B cell heterogeneity in the teleost kidney: evidence for a maturation gradient from anterior to posterior kidney. J Immunol 174: 6608-6616.

24. Zwollo P, Haines A, Rosato P, Gumulak-Smith J (2008): Molecular and cellular analysis of $B$ cell populations in the 
rainbow trout using Pax5 and immunoglobulin markers. Dev Comp Immunol 32: 1482-1496.

25. Zwollo P, Mott K, Barr M (2010): Comparative analyses of $\mathrm{B}$ cell populations in trout kidney and mouse bone marrow: establishing "B cell signatures". Dev Comp Immunol 34: 1291-1299.

26. Bromage ES, Kaattari IM, Zwollo P, Kaattari SL (2004): Plasmablast and plasma cell production and distribution in trout immune tissues. J Immunol 173: 7317-7323.

27. Ye J, Kaattari I, Kaattari S (2011): Plasmablasts and plasma cells: reconsidering the organization of the teleost immune response. Dev Comp Immunol 35: 1273-1281.

28. Barr M, Mott K, Zwollo P (2011): Defining terminally differentiating $\mathrm{B}$ cell populations in rainbow trout immune tissues using the transcription factor XbpI. Fish Shellfish Immunol 31: 727-735.

29. Hikima J, Lennard ML, Wilson MR, et al. (2005): Evolution of vertebrate E protein transcription factors: comparative analysis of the E-protein gene family in Takifugu rubripes and humans. Physiol Genomics 21: 144-151.

30. Hikima J, Middleton DL, Warr GW (2005): Regulation of immunoglobulin gene transcription in teleost fish: identification, expression, and functional properties of E2A in channel catfish. Immunogenetics 57: 273-282.

31. MacMurray E, Barr M, Bruce A, et al. (2013): Alternative splicing of the trout Pax5 gene and identification of novel B cell populations using Pax5 signatures. Dev Comp Immunol 41: 270-281.

32. Ohtani M, Miyadai T, Hiroishi S (2006): B-lymphocyteinduced maturation protein-1 (Blimp-1) gene of torafugu (Takifugu rubripes). Fish Shellfish Immunol 20: 409-413.

33. Zwollo P (2018): The humoral immune system of anadromous fish. Dev Comp Immunol 80: 24-33.

34. Schouten J, Clister T, Bruce A, et al. (2013): Sockeye salmon retain immunoglobulin-secreting plasma cells throughout their spawning journey and post-spawning. Dev Comp Immunol 40: 202-209.

35. Ye J, Kaattari IM, Ma C, Kaattari S (2013): The teleost humoral immune response. Fish Shellfish Immunol 35: 17191728.

36. Cain KD, Jones DR, Raison RL (2002): Antibody-antigen kinetics following immunization of rainbow trout (Oncorhynchus mykiss) with a T-cell dependent antigen. Dev Comp Immunol 26: 181-190. 